\title{
Morphology, genetic characterization and molecular phylogeny of pinworm Skrjabinema longicaudatum n. sp. (Oxyurida: Oxyuridae) from the endangered Tibetan antelope Pantholops hodgsonii (Abel) (Artiodactyla: Bovidae)
}

\author{
Yi-Fan Cao ${ }^{1,2+}$, Hui-Xia Chen ${ }^{3+}$, Yang Li ${ }^{3}$, Dang-Wei Zhou ${ }^{1,4^{*}}$, Shi-Long Chen ${ }^{1,4}$ and Liang Li $3^{*}$
}

\begin{abstract}
Background: The Tibetan antelope Pantholops hodgsonii (Abel) (Artiodactyla: Bovidae) is an endangered species of mammal endemic to the Qinghai-Tibetan Plateau. Parasites and parasitic diseases are considered to be important threats in the conservation of the Tibetan antelope. However, our present knowledge of the composition of the parasites of the Tibetan antelope remains limited.

Methods: Large numbers of nematode parasites were collected from a dead Tibetan antelope. The morphology of these nematode specimens was observed using light and scanning electron microscopy. The nuclear and mitochondrial DNA sequences, i.e. small subunit ribosomal DNA (18S), large subunit ribosomal DNA (285), internal transcribed spacer (ITS) and cytochrome c oxidase subunit 1 (cox1), were amplified and sequenced for molecular identification. Moreover, phylogenetic analyses were performed using maximum likelihood (ML) inference based on 285 and $185+$ $285+\operatorname{cox} 1$ sequence data, respectively, in order to clarify the systematic status of these nematodes.

Results: Integrated morphological and genetic evidence reveals these nematode specimens to be a new species of pinworm Skrjabinema longicaudatum (Oxyurida: Oxyuridae). There was no intraspecific nucleotide variation between different individuals of S. longicaudatum n. sp. in the partial 18S, 28S, ITS and cox1 sequences. However, a high level of nucleotide divergence was revealed between the new species and its congeners in 285 (8.36\%) and ITS (20.3-23.7\%) regions, respectively. Molecular phylogenetic results suggest that the genus Skrjabinema should belong to the
\end{abstract}

*Correspondence: dangweizhou@sina.com; liangliangex369@126.com ${ }^{\dagger}$ Yi-Fan Cao and Hui-Xia Chen contributed equally to this work ${ }^{1}$ Key Laboratory of Adaptation and Evolution of Plateau Biota (AEPB), Northwest Institute of Plateau Biology, Chinese Academy of Sciences, Xining 810008, Qinghai, People's Republic of China

${ }^{3}$ Key Laboratory of Animal Physiology, Biochemistry and Molecular Biology of Hebei Province, College of Life Sciences, Hebei Normal University, Shijiazhuang 050024, Hebei Province, People's Republic of China

Full list of author information is available at the end of the article

\section{Background}

The Tibetan antelope Pantholops hodgsonii (Abel) (Artiodactyla: Bovidae) is an endangered species of mammal endemic to the Qinghai-Tibetan Plateau. The population of the Tibetan antelope has been declined severely, because of the loss and fragmentation of its habitat and commercial poaching [1,2]. The latest estimate of the global population of the Tibetan antelope is

c) The Author(s) 2020. This article is licensed under a Creative Commons Attribution 4.0 International License, which permits use, sharing, adaptation, distribution and reproduction in any medium or format, as long as you give appropriate credit to the original author(s) and the source, provide a link to the Creative Commons licence, and indicate if changes were made. The images or other third party material in this article are included in the article's Creative Commons licence, unless indicated otherwise in a credit line to the material. If material is not included in the article's Creative Commons licence and your intended use is not permitted by statutory regulation or exceeds the permitted use, you will need to obtain permission directly from the copyright holder. To view a copy of this licence, visit http://creativeco mmons.org/licenses/by/4.0/. The Creative Commons Public Domain Dedication waiver (http://creativecommons.org/publicdomain/ zero/1.0/) applies to the data made available in this article, unless otherwise stated in a credit line to the data. 
subfamily Oxyurinae (Oxyuroidea: Oxyuridae), instead of the subfamily Syphaciidae or Skrjabinemiinae in the traditional classification, as it formed a sister relationship to the genus Oxyuris.

Conclusions: A new species of pinworm Skrjabinema longicaudatum n. sp. (Oxyurida: Oxyuridae) is described. Skrjabinema longicaudatum n. sp. represents the first species of Oxyurida (pinworm) and the fourth nematode species reported from the Tibetan antelope. Our results contribute to the knowledge of the species diversity of parasites from the Tibetan antelope, and clarify the systematic position of the genus Skrjabinema.

Keywords: Tibetan antelope, Parasite, Nematoda, Morphology, Genetic data, Phylogeny

100,000-150,000 mature individuals (https://www.iucnr edlist.org/species/15967/50192544). This species is listed as "Near Threatened" in the IUCN Red List of Threatened Species $^{\mathrm{TM}}$ and also listed as Class I (Endangered in China) National Protected Wild Animal Species in China.

Parasites and parasitic diseases are considered to be important threats in wildlife conservation, as they can potentially impair the health of wildlife, decrease fitness, cause population declines and even contribute to local extinction [3-7]. Parasites are also significant pathogens of the Tibetan antelope [1, 2]. To date, 17 species of ectoparasites and endoparasites have been reported from the Tibetan antelope, including 5 species of oestrid and hippoboscid flies, 7 species of protozoans, 2 species of tapeworms and 3 species of nematodes [1, 2, 8-12].

In the present study, some nematode specimens were collected from the digestive tract of the Tibetan antelope, which were identified morphologically as a new species of the genus Skrjabinema (Oxyurida: Oxyuridae) using light and scanning electron microscopy. The nuclear and mitochondrial DNA sequences, i.e. small subunit ribosomal DNA (18S), large subunit ribosomal DNA (28S), internal transcribed spacer (ITS) and cytochrome $c$ oxidase subunit 1 ( $\operatorname{cox} 1)$, were also amplified and sequenced for molecular identification of this species. Moreover, in order to clarify the systematic status of the genus Skrjabinema, phylogenetic analyses were performed using maximum likelihood (ML) inference based on $28 S$ and $18 S+28 S+\operatorname{cox} 1$ sequence data, respectively.

\section{Methods}

\section{Parasite collection}

A Tibetan antelope died naturally in the Hohxil National Nature Reserve, Qinghai Province, China. The digestive tract of this Tibetan antelope was sent to the Key Laboratory of Adaptation and Evolution of Plateau Biota (AEPB), Northwest Institute of Plateau Biology, Chinese Academy of Sciences for examination of parasites. Large numbers of nematode parasites were isolated from the caecum and colon. Specimens were fixed and stored in in $5 \%$ glycerine plus $70 \%$ ethanol until study.

\section{Morphological observations}

For light microscopical studies, nematodes were cleared in lactophenol. Drawings were made using a Nikon microscope drawing attachment. For scanning electron microscopy (SEM), the anterior and posterior parts of specimens were re-fixed in $4 \%$ formaldehyde solution, post-fixed in $1 \%$ OsO4, dehydrated via an ethanol series and acetone, and then critical-point dried. Samples were coated with gold and examined using a Hitachi S-4800 scanning electron microscope at an accelerating voltage of $20 \mathrm{kV}$. Measurements (the range, followed by the mean values in parentheses) are given in micrometers $(\mu \mathrm{m})$ unless otherwise stated.

\section{Molecular protocols}

Three female specimens were randomly chosen for molecular analysis. Genomic DNA from each sample was extracted using a Column Genomic DNA Isolation Kit (Shanghai Sangon, China) according to the manufacturer's instructions. The partial $18 \mathrm{~S}$ region was amplified by polymerase chain reaction (PCR) using the forward primer 18S-F (5'-CGC GAA TRG CTC ATT ACA ACA GC-3') and the reverse primer 18S-R (5'-GGG CGG TAT CTG ATC GCC-3') [13]. The partial $28 S$ region was amplified by PCR using the forward primer 28S-F (5'AGC GGA GGA AAA GAA ACT AA-3') and the reverse primer 28S-R (5'-ATC CGT GTT TCA AGA CGG G-3') [14]. The ITS-1 region of nuclear rDNA was amplified by PCR using the forward primer SS1 (5'-GTT TCC GTA GGT GAA CCT GCG-3') and the reverse primer SS2R (5'-AGT GCT CAA TGT GTC TGC AA-3'). The ITS-2 region of nuclear rDNA was amplified by PCR using the forward primer NC13 (5'-ATC GAT GAA GAA CGC AGC-3') and the reverse primer NC2 (reverse: 5'-TTA GTT TCT TTT CCT CCG CT-3') [15]. The partial cox1 region was amplified by $\mathrm{PCR}$ using the forward primer cox1F2020 (5'-GAG TAC TAA TCA TAA GGA TAT TGG-3') and the reverse primer cox1R2020 (5'-ACA TAA ACY TCA GGA TGA CCA-3'), both newly designed in present study. The cycling conditions are as described previously [16]. PCR products were checked on GoldView-stained 1.5\% agarose gels and purified with Column PCR Product Purification Kit (Shanghai Sangon, China). 
Sequencing was carried out using a Dye Deoxy Terminator Cycle Sequencing Kit (v.2, Applied Biosystems, California, USA) and an automated sequencer (ABI-PRISM 377). Sequences were aligned using ClustalW2. The DNA sequences obtained herein were compared (using the algorithm BLASTn) with those available in the National Center for Biotechnology Information (NCBI) database (https://www.ncbi.nlm.nih.gov).

\section{Phylogenetic analyses}

Phylogenetic trees were constructed using maximum likelihood (ML) inference with MEGA X software based on the partial $28 S$ and $18 S+28 S+\operatorname{cox} 1$ sequence data, respectively. Pseudonymus spirotheca (Oxyurida: Thelastomatoidea: Pseudonymidae) was treated as the outgroup. The ingroup includes the representatives of the Oxyuridae with the $28 S$ and $18 S+28 S+\operatorname{cox} 1$ sequence data available in the GenBank database. We used a builtin function in the software MEGA $\mathrm{X}$ to select a bestfitting substitution model for the present sequences according to the Bayesian information criterion. The K2 (Kimura 2-parameter) + G model for the $28 S$ sequence data, and the HKY (Hasegawa-Kishino-Yano) + G + I model for the $18 S+28 S+\operatorname{cox} 1$ sequence data were identified as the optimal nucleotide substitution model, respectively. Nodal support for ML trees were tested using 1000 bootstrap replications, and bootstrap values exceeding $80 \%$ were showed in the phylogenetic trees.

\section{Results}

Family Oxyuridae Cobbold, 1864

Genus Skrjabinema Werestschagin, 1926

\section{Skrjabinema longicaudatum n. sp.}

\section{Type-host}

Tibetan antelope Pantholops hodgsonii (Abel) (Artiodactyla: Bovidae: Caprinae).

\section{Type-locality}

Hoh Xil Nature Reserve near Wudaoliang ( $35^{\circ} 26^{\prime} \mathrm{N}, 93^{\circ}$ $\left.17^{\prime} \mathrm{E}\right)$, Qinghai Province, China.

\section{Type-specimens}

Holotype: male (HBNU-N-2020M001L); allotype: female (HBNU-N-2020M002L); paratypes: 9 females (HBNUN-2020M003L) deposited in the College of Life Sciences, Hebei Normal University, Hebei Province, China; paratypes: 2 males and 100 females (KLAEPB No.019001) deposited in the Key Laboratory of Adaptation and
Evolution of Plateau Biota, Northwest Institute of Plateau Biology, Chinese Academy of Sciences, Qinghai Province, China.

\section{Site in host \\ Caecum and colon.}

\section{Prevalence and intensity}

A single Tibetan antelope examined with 124 worms.

\section{ZooBank registration}

To comply with the regulations set out in Article 8.5 of the amended 2012 version of the International Code of Zoological Nomenclature (ICZN) [17], details of the new species have been submitted to ZooBank. The Life Science Identifier (LSID) of the article is urn:lsid:zoobank.org:pub:9194626F-7C3B445C-BD36-0AF06E39C46F. The LSID for the new name Skrjabinema longicaudatum is urn:lsid:zoobank. org:act:3A5AB2D4-5B82-4CBE-8CF8-76B97783694E.

\section{Etymology}

The specific epithet is derived from a combination of the Latin words longus - (long) and caudatum- (cauda), and refers to the unusually long tail in the female of the new species.

\section{Description \\ General}

Small-sized, whitish nematodes. Body cylindrical, maximum width at slightly posterior to mid-body. Cephalic vesicle indistinct in both sexes (Fig. 1a, c). Lateral alae present in both sexes (Figs. 1c, 2a, c, d). Sexual dimorphism prominent in cephalic structure (Figs. 1b, 3a, b, d). Cuticle with remarkable transverse annulations in anterior part of body (Fig. 2d, e). Buccal cavity very small, without cuticular tooth or other ornamentation. Oesophagus divided into short pharynx, cylindrical corpus, indistinct isthmus and ovoid posterior bulb with valves (Fig. 1a). Nerve-ring situated at about $1 / 4$ of total oesophageal length (Fig. 1a). Excretory pore located in body wall depression, posterior to oesophago-intestinal junction (Figs. 1a, 2a, b). Deirids not observed.

\section{Male}

[Based on 3 mature specimens; Figs. 1c, e, g, h, 3d]: Body 1.92-2.85 (2.38) mm long; maximum width 141-151 (146). Oral aperture simple, triradiate, surrounded by three small, more or less triangular lips with small apical median notch (Fig. 3d). Interlabia or 
interlabial projections absent (Fig. 3d). Oesophagus 400-454 (427) in total length, representing 15.7-20.9 (17.6)\% of body length; pharynx + corpus + isthmus 255-308 (280) long, size of bulb 143-146 (145) $\times$ 131-132 (132). Nerve-ring at 170-200 (185) and excretory pore at 760-890 (828) from cephalic extremity, respectively. Lateral alae narrow, extending from about level of nerve-ring to anterior region of cloaca (Fig. 1c). Posterior extremity of body distinctly curved ventrally (Fig. 1h). Spicule single, pointed at distal end, 74-81 (76.7) long, representing 3.15-3.85 (3.43) \% of body length (Fig. 1e, g, h). Gubernaculum small, well sclerotized, about 48 long (Fig. 1g, h). Caudal papillae large, 3 pairs in total, arranged as follows: 1 pair precloacal, 1 pair paracloacal and 1 pair postcloacal (Fig. 1g). Preventral, median finger-like protuberance present (Fig. 1h). Tail 33 long, ending in short fingerlike tip (Fig. 1g, h). Phasmids present slightly posterior to cloaca.

\section{Female}

[Based on 10 mature specimens; Figs. 1a, b, d, f, i, 2a-i, 3a-c, e, f): Body 9.92-12.1 (11.1) mm long; maximum width 396-574 (475). Cephalic extremity with three anchor-shaped lips, each lip with 2 triangular lateral lobes not attached to cephalic rim (Figs. 1b, 3a-c). Interlabia digitiform, between lateral lobes of lips (Figs. 1b, $3 \mathrm{a}, \mathrm{b})$. Four large cephalic papillae and 2 small amphidial pores present (Figs. 1b, 3a, b). Oesophagus 832-881 (853) in total length, representing 6.98-8.78 (7.75) \% of body length; pharynx + corpus + isthmus 634-703 (671) long, size of bulb 168-188 (181) × 139-188 (161). Nerve-ring at 198-248 (225) and excretory pore at 1.24-1.92 (1.77) $\mathrm{mm}$ from cephalic extremity, respectively. Lateral alae extending from long distance posterior to base of cephalic extremity and ending at about middle of tail (Fig. 2a, c, $\mathrm{d}, \mathrm{f}, \mathrm{h}$ ). Vulva a transverse slit, very small, with rudimentary lips observed under SEM, located at 2.97-3.37 (3.16) $\mathrm{mm}$ from cephalic extremity, representing 25.1-31.1\% (28.7\%) of body length (Figs. 1d, 3e). Egg asymmetrical, flattened at one side, embryonated or nonembryonated, thick-shelled, with smooth surface, 40-59 (51) × 20-40 (30) $(n=20)$ (Figs. 1i, 2i, 3f). Anus with small pre anal lip (Fig. 2g). Tail slender, very long, 2.63-3.13 (2.90) mm, with pointed tip, representing 23.0-27.7 (26.3) \% of body length (Figs. 1f, 3f). Phasmids not observed.

\section{Genetic characterization Partial 185 region}

Three $18 S$ sequences of S. longicaudatum n. sp. obtained herein were all $678 \mathrm{bp}$ in length and represent one genotype. There are two species of Skrjabinema with $18 S$ sequence registered in GenBank, namely S. kamosika (AB699690) and Skrjabinema sp. (EF180060). Pairwise comparison of $18 S$ sequences between S. longicaudatum n. sp. and the two species of Skrjabinema displayed $0.29-1.18 \%$ nucleotide divergence. The $18 S$ sequences of $S$. longicaudatum $\mathrm{n}$. sp. are deposited in the GenBank database under the accession numbers MW020179-MW020181.

\section{Partial ITS region}

Three ITS sequences of S. longicaudatum n. sp. obtained herein were all $1079 \mathrm{bp}$ in length and represent one genotype. There are two species of Skrjabinema with ITS sequence registered in GenBank, namely S. kamosika (AB699691) and Skrjabinema sp. (AB367796). Pairwise comparison of ITS sequences between $S$. longicaudatum $n$. sp. and the other two species of Skrjabinema displayed 20.3-23.7\% nucleotide divergence. The ITS sequences of S. longicaudatum n. sp. are deposited in the GenBank database under the accession numbers MW020057-MW020059.

\section{Partial 28S region}

Three $28 S$ sequences of S. longicaudatum n. sp. obtained herein were all $819 \mathrm{bp}$ in length and represent one genotype. There is only one species of Skrjabinema, namely $S$. ovis (KY990019) with $28 S$ sequence registered in GenBank. Pairwise comparison of ITS sequences between $S$. longicaudatum n. sp. and S. ovis displayed $8.36 \%$ nucleotide divergence. The $28 S$ sequences of $S$. longicaudatum n. sp. are deposited in the GenBank database under the accession numbers MW020098-MW020100.

\section{Partial cox 1 region}

Three cox 1 sequences of $S$. longicaudatum $\mathrm{n}$. sp. obtained herein was $360 \mathrm{bp}$ in length. There is no species of $S k r$ jabinema with cox1 sequence registered on GenBank. The cox 1 sequences of S. longicaudatum $\mathrm{n}$. sp. are deposited in the GenBank database under the accession numbers MW021552-MW021554.

\section{Phylogenetic analyses}

Phylogenetic trees based on the partial $28 S$ sequence data showed that representatives of the family Oxyuridae were divided into three monophyletic clades. Clade I included members of the genera Syphacia, Passalurus, Syphatineria, Syphabulea and Rauschtineria, representing the subfamily Syphaciinae. Clade II contained species of the genera Oxyuris and Skrjabinema, representing the subfamily Oxyurinae. Clade III included species of the genus Trypanoxyuris, representing the subfamily Enterobiinae (Fig. 4). Skrjabinema longicaudatum n. sp. displayed a sister relationship to S. ovis. 

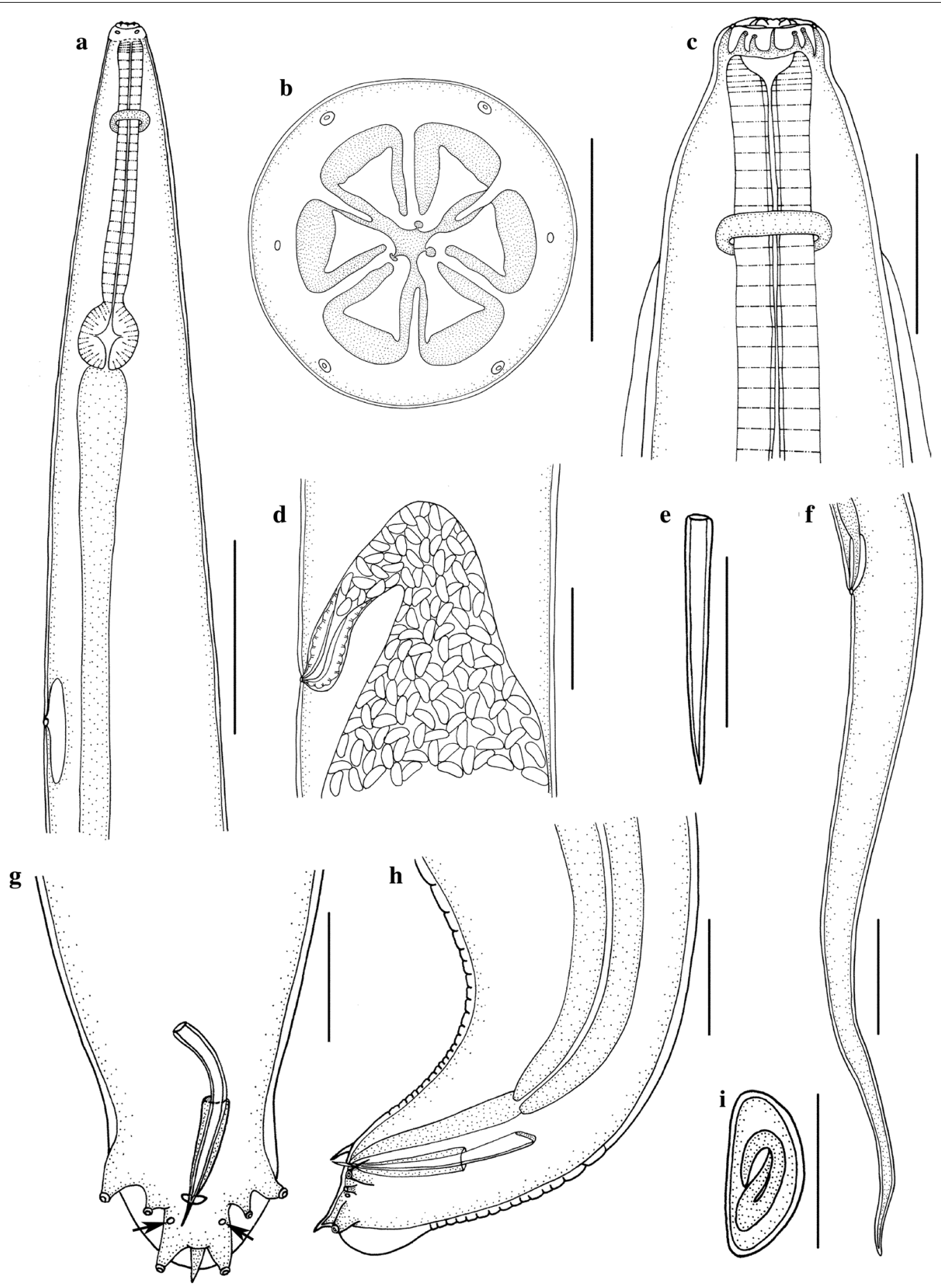

Fig. 1 Skrjabinema longicaudatum n. sp. (Oxyurida: Oxyuridae) from the endangered Tibetan antelope Pantholops hodgsonii (Abel) (Artiodactyla: Bovidae) in China. a Anterior part of female, lateral view. b Cephalic extremity of female, apical view. c Anterior part of male, dorsal view. $\mathbf{d}$ Region of vulva, lateral view. e Spicule. f Posterior extremity of female, lateral view. $\mathbf{g}$ Posterior extremity of male (phasmids arrowed), ventral view. $\mathbf{h}$ Posterior extremity of male, lateral view. i Egg. Scale-bars: $\mathbf{a}, \mathbf{f}, 500 \mu \mathrm{m} ; \mathbf{b}, \mathbf{e}, \mathbf{g}, \mathbf{h}, \mathbf{i}, 50 \mu \mathrm{m} ; \mathbf{c}, 100 \mu \mathrm{m} ; \mathbf{d}, 200 \mu \mathrm{m}$

Phylogenetic tree constructed based on the $18 S+28 S+\operatorname{cox} 1$ sequence data had similar topology to the phylogenetic results using the partial $28 S$ sequence data, in which representatives of the Oxyuridae also divided into three monophyletic clades (Fig. 5). Species of Trypanoxyuris and Enterobius formed clade I, 


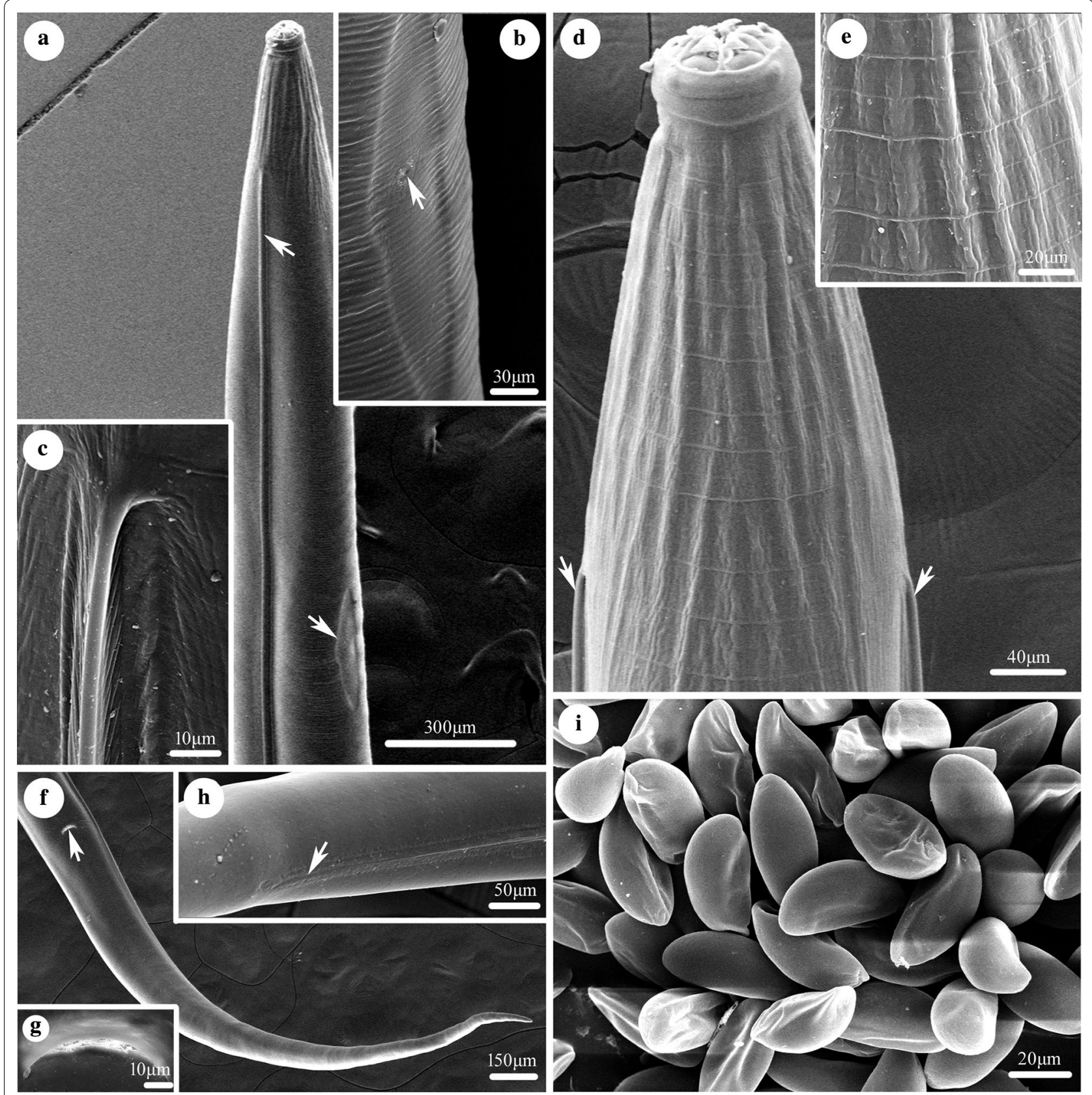

Fig. 2 Scanning electron micrographs of Skrjabinema longicaudatum n. sp. (Oxyurida: Oxyuridae) from the endangered Tibetan antelope Pantholops hodgsonii (Abel) (Artiodactyla: Bovidae) in China. a Anterior part of female (lateral ala and depressed region around excretory pore arrowed), lateral view. b Magnified image of depressed region and excretory pore (excretory pore arrowed). c Magnified image of the original position of lateral ala. $\mathbf{d}$ Anterior part of female (lateral alae arrowed), dorsal view. e Magnified image of transverse annulations in the anterior part of body. $\mathbf{f}$ Posterior extremity of female (anus arrowed), ventral view. $\mathbf{g}$ Magnified image of anus. $\mathbf{h}$ Magnified image of the ending position of caudal ala. i Magnified image of eggs in uterus in different views

representing the subfamily Enterobiinae. The members of Syphabulea and Syphacia grouped together (clade II), belonging the subfamily Enterobiinae. Clade III included representatives of Oxyuris and Skrjabinema, representing the subfamily Oxyurinae. Skrjabinema longicaudatum n. sp. clustered together with S. kamosika. 

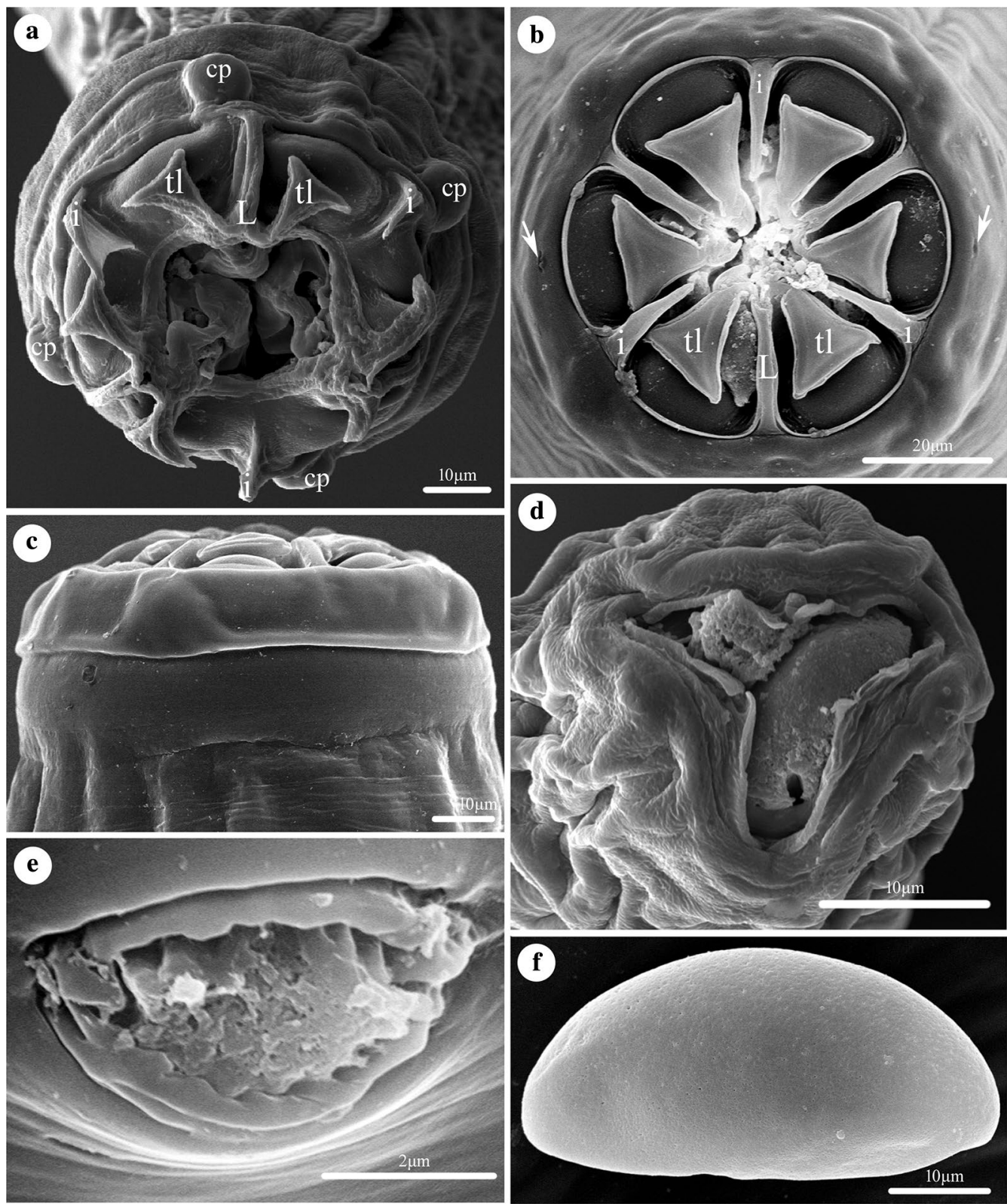

Fig. 3 Scanning electron micrographs of Skrjabinema longicaudatum n. sp. (Oxyurida: Oxyuridae) from the endangered Tibetan antelope Pantholops hodgsonii (Abel) (Artiodactyla: Bovidae) in China. a Cephalic region of female, sub-apical view. b Cephalic region of female (amphidial pores arrowed), apical view. c Cephalic region of female, lateral view. $\mathbf{d}$ Cephalic region of male, apical view. e Magnified image of vulva. $\mathbf{f}$ Magnified image of egg, lateral view

\section{Discussion}

The genus Skrjabinema Werestschagin, 1926 (Oxyuridea: Oxyuridea) currently includes 10 nominal species reported from various ruminants worldwide, namely S. alata Mönnig, 1932, S. africana Mönnig, 1932, S. caprae Schad, 1959, S. chubuki Gagarin \& Sapozhnikov, 1968, S. kamosika Hasegawa, Sato, Suzuki \& Kaneshiro, 2012, S. ovis (Skrjabin, 1915), S. parva Dikmans, 1942, S. rupicaprae Böhm \& Gebauer, 1930, S. skrjabini Gagarin \& Sapozhnikov, 1968 and S. tarandi Skrjabin \& Mizkewitsch, 1930 [18-24]. However, some of these species have not been sufficiently well described, especially the details of cephalic structure.

Skrjabinema ovis is the type-species of this genus, which has been widely reported from goats and sheep in Asia, Europe, America and Australia [21]. This 
species has been recorded from Capra aegagrus hircus (Linnaeus), Ovis aries Linnaeus and Procapra przewalskii Büchner in China [25]. The new species differs from $S$. ovis in the absence of cephalic vesicle in females ( $v s$ the presence of remarkable cephalic vesicle in the female in S. ovis), slightly shorter spicules (0.074-0.081 $\mathrm{mm}$ long in the new species $v s 0.09-0.12 \mathrm{~mm}$ long in S. ovis $)$ and longer gubernaculum $(0.048 \mathrm{~mm}$ long in S. longicaudatum n. sp. vs $0.019-0.025 \mathrm{~mm}$ long in the latter). Skrjabinema longicaudatum n. sp. has the spicule without a dilated proximal end, longer gubernaculum (0.019-0.025 $\mathrm{mm}$ long) and the caudal alae ending about half-way along the tail in female, which is different from that of $S$. parva (the proximal end of spicule extends into a goblet-shaped, the gubernaculum 0.01-0.016 $\mathrm{mm}$ long and the caudal alae ending close to the tail tip in female). The absence of subinterlabial projections in the cephalic region in the male distinguishes the new species from S. kamosika, $S$. tarandi and S. caprae (the presence of sub-interlabial projections in the cephalic end in the male). Moreover, the caudal alae of the female in $S$. tarandi and $S$. caprae are very long (ending near the tail tip $v s$ caudal alae ending at about half the tail length in the female of S. longicaudatum). Skrjabinema longicaudatum $\mathrm{n}$. sp. differs from S. rupicaprae by having a larger body size of male (1.92-2.85 vs $1.54-1.79 \mathrm{~mm}$ long in $S$. rupicaprae), a relatively shorter spicule (spicule representing 3.15-3.85\% of body length in the former $v s$ representing $4.47-5.20 \%$ of body length in the latter) and a slightly longer gubernaculum $(0.048 \mathrm{~mm}$ long in the new species $v s 0.025 \mathrm{~mm}$ long in $S$. rupicaprae). The new species can be distinguished from S. chubuki and S. skrjabini by having morphologically different lips in the female (triangular lateral lobes of lip small, not attached to the cephalic rim in S. longicaudatum n. sp. $v s$ triangular lateral lobes of lip very large, attached to the cephalic rim in the latter two species).

Mönnig [18] described S. alata and S. africana based on only female specimens in South Africa. Both species are differentiated from the new species by distinctly smaller body size of female (4.61-5.80 mm long in S. alata and S. africana vs 9.92-12.1 mm long in $S$. longicaudatum n. sp.). In addition, S. africana differs

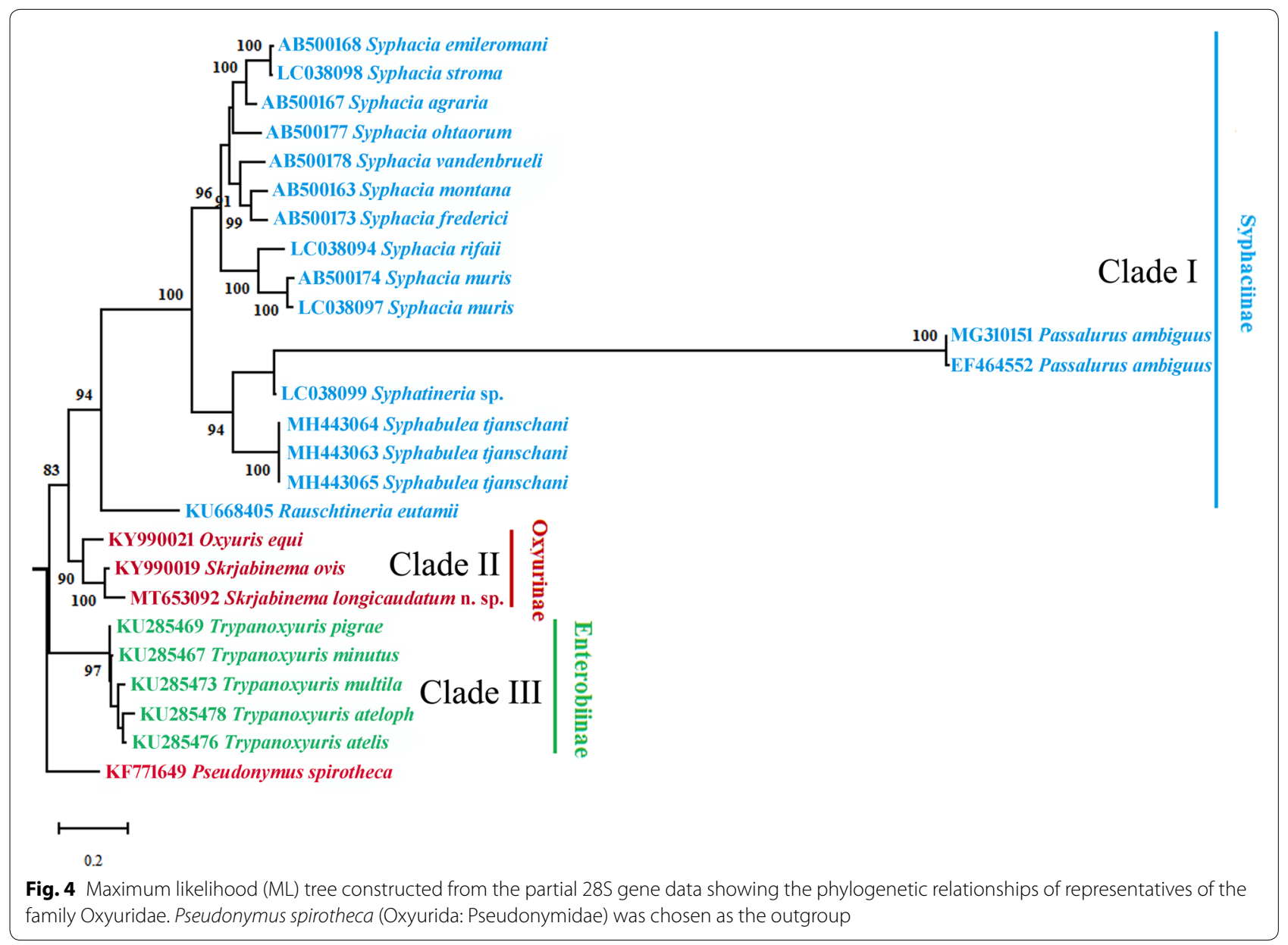




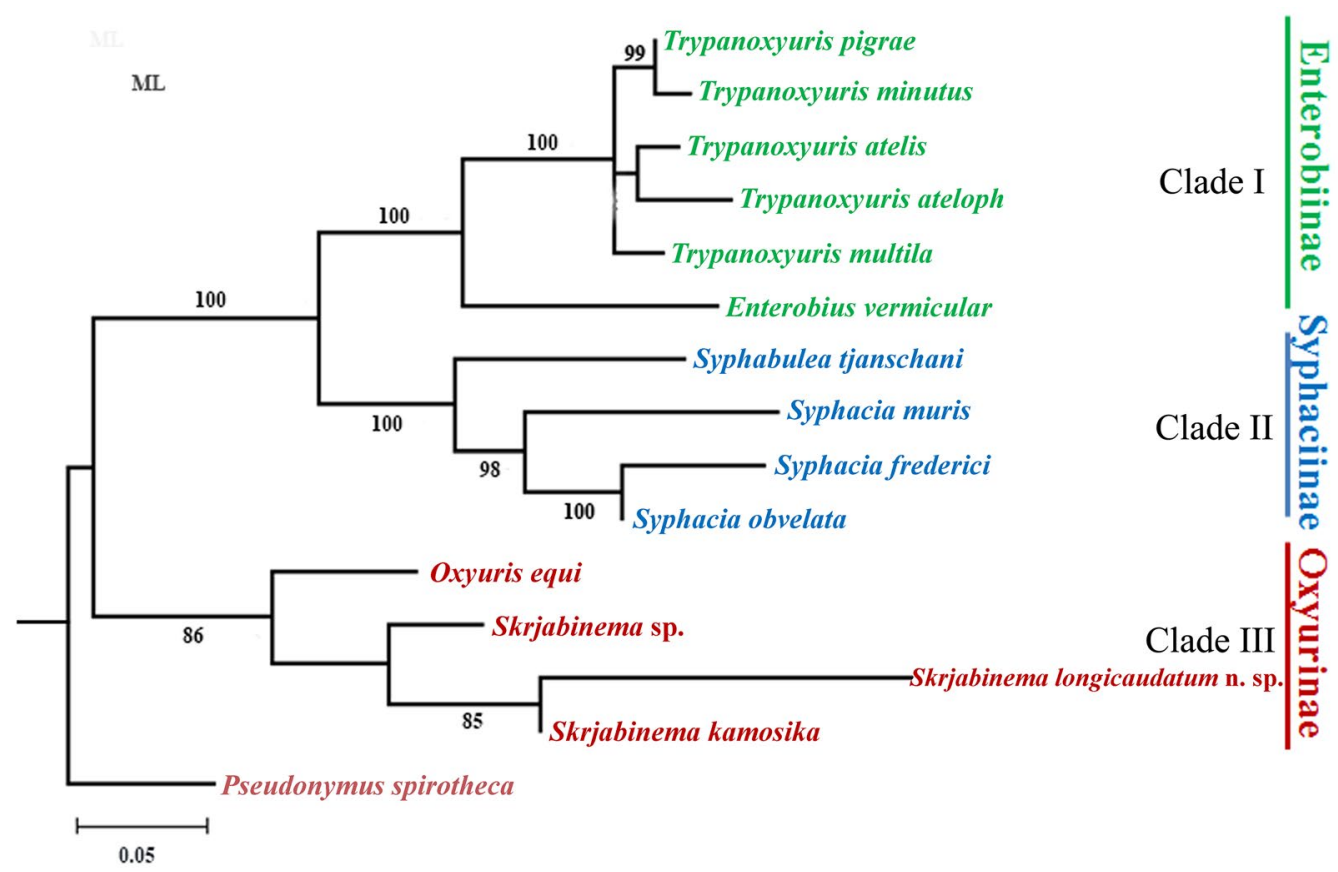

Fig. 5 Maximum likelihood (ML) tree constructed from the partial 18+28S+cox1 gene data showing the phylogenetic relationships of representatives of the family Oxyuridae. Pseudonymus spirotheca (Oxyurida: Pseudonymidae) was chosen as the outgroup

from S. longicaudatum n. sp. by having the caudal alae of the female ending very near the tail tip ( $v s$ caudal alae ending at about half of tail length in S. longicaudatum). Skrjabinema alata differs from the new species by having a relatively longer oesophagus (oesophagus representing $12.8-14.3 \%$ of body length in S. alata vs representing $6.98-8.78 \%$ of body length in S. longicaudatum). Moreover, S. longicaudatum n. sp. can be easily distinguished from all its congeners by the unusually long tail in the female (tail $2.63-3.13 \mathrm{~mm}$, representing $23.0-27.7 \%$ of body length $v s$ not over $1.60 \mathrm{~mm}$, representing $6.68-20.6 \%$ of body length in the other species of Skrjabinema).

It is difficult to identify and discriminate the pinworms using traditional methods due to their extraordinary morphological similarity and sometimes the male worms being unavailable [26]. Molecular approaches have been employed for identification and discrimination of pinworms in some previous studies [24, 26-32]. However, to date, genetic data of pinworms available in the GenBank database remain limited, which has hindered the further studies of DNA-based taxonomy, population genetics and phylogenetics of this group of nematode parasites.

In the present study, we amplified and sequenced the partial $18 S, 28 S$, ITS and cox 1 alignments of our specimens for future use in the molecular identification of this new species. There was no intraspecific nucleotide variation between different individuals of $S$. longicaudatum n. sp. in the partial $18 S, 28 S$, ITS and cox 1 sequences. However, a high level of nucleotide divergence was revealed between the new species and its congeners in $28 S(8.36 \%)$ and ITS (20.3-23.7\%) regions, respectively. The more slowly evolving $18 S$ gene may be not suitable for species identification of Skrjabinema, because of very low level of interspecific nucleotide variation detected between different species of Skrjabinema (0.29-1.18\%). However, the $18 S$ gene could be chosen to provide resolution at higher taxonomic levels. It is the first time to report the cox 1 sequence of $S k r$ jabinema species.

The systematic position of Skrjabinema is still under debate. Skrjabin [22] placed this genus into the subfamily Syphaciinae Railliet, 1916 in Syphaciidae Skrjabin \& Schikhobalova, 1951. Erkulov \& Moldopiyazova [33] proposed a new subfamily Skrjabinemiinae for the genera Skrjabinema and Citellina. Hugot [34] reduced the family Syphaciidae to a subfamily in Oxyuridae and did not recognise the validity of Skrjabinemiinae. The present phylogenetic analyses based on the partial $28 S$ and $18 S+28 S+\operatorname{cox} 1$ sequence data supported the genus Skrjabinema to be a member of the subfamily Oxyurinae, with a sister relationship with the genus Oxyuris, which agrees well with recent molecular phylogenetic results [26]. 
Our present knowledge of the composition of the nematode parasites of the Tibetan antelope remains limited. In the light of available literature, only three species of nematodes have been recorded from the Tibetan antelope, including Nematodirus sp., Marshallagia mongolica Schumakoviech, 1938 and M. marshalli (Ransom 1907) (Rhabditida: Strongyloidea) [9-11]. Skrjabinema longicaudatum n. sp. represents the first species of Oxyurida (pinworm) and the fourth nematode species reported from the Tibetan antelope.

\section{Conclusions}

A new species of pinworm Skrjabinema longicaudatum n. sp. (Oxyurida: Oxyuridae) is described using light and scanning electron microscopy, based on specimens collected from the endangered Tibetan antelope. Skrjabinema longicaudatum $\mathrm{n}$. sp. represents the first species of Oxyurida (pinworm) and the fourth nematode species reported from the Tibetan antelope. The nuclear and mitochondrial DNA sequences (i.e. 18S, 28S, ITS and $\operatorname{cox} 1$ ) were amplified and sequenced for molecular identification of this new species. Phylogenetic analyses using maximum likelihood (ML) inference based on $28 \mathrm{~S}$ and $18 \mathrm{~S}+28 \mathrm{~S}+\operatorname{cox} 1$ sequence data suggested that the genus Skrjabinema should belong to the subfamily Oxyurinae (Oxyuroidea: Oxyuridae), instead of the subfamily Syphaciidae or Skrjabinemiinae in the traditional classification, as it formed a sister relationship to the genus Oxyuris. Our results contribute to the knowledge of the species diversity of parasites from the Tibetan antelope, provided useful genetic data for molecular identification and phylogeny of the Oxyuridae, and also clarified the systematic position of the genus Skrjabinema.

\footnotetext{
Abbreviations

AEPB: Key laboratory of adaptation and evolution of plateau biota; SEM: Scanning electron microscopy; K2: Kimura 2-parameter; HKY: HasegawaKishino-Yano; PCR: Polymerase chain reaction; ML: Maximum likelihood; 18S: Small subunit ribosomal DNA; 28S: Large subunit ribosomal DNA; ITS: Internal transcribed spacer; cox1: Cytochrome coxidase subunit 1; L: Lip; i: Interlabia; tl: Triangular lateral lobes of lip; cp: Cephalic papillae.
}

\section{Acknowledgements}

The authors are grateful to Professor Hideo Hasegawa (Faculty of Medicine, Oita University, Japan) for providing important literature. The authors wish to thank the officials and staff of Bureau of Hohxil National Nature Reserve for their assistance with collection of the parasite samples.

\section{Authors' contributions}

YFC, DWZ and SLC carried out sample collection. LL, HXC, DWZ, YFC and YL identified the nematode specimens and analyzed data. LL, HXC, YFC and DWZ designed the study, conducted the phylogenetic analyses and wrote the manuscript. All authors read and approved the final manuscript.

\section{Funding}

This study was supported by the Natural Science Foundation of Hebei Province (No. C2019205094), the Basic Research Program of Qinghai Province (No. 2017-ZJ-723; 2017-ZJ-702), the Support Program for 100 Excellent Innovative
Talents of Hebei Province (No. SLRC2019033), the Strategic Priority Research Program of the Chinese Academy of Sciences (No. XDB26000000), the Youth Top Talent Support Program of Hebei Province for Dr. Liang Li and the Natural Science Foundation of Hebei Normal University for Dr. Hui-Xia Chen (No. L2020B15).

\section{Availability of data and materials}

The nuclear and mitochondrial DNA sequences of Skrjabinema longicaudatum n. sp. obtained in this study were deposited in the GenBank database under the accession numbers MW021552-MW021554 (cox1 sequences), MW020057MW020059 (ITS sequences), MW020098-MW020100 (28S sequences), MW020179-MW020181 (18S sequences). Type specimens of the new species were deposited in College of Life Sciences, Hebei Normal University, Hebei Province under the accession numbers HBNU-N-2020M001-3L, and the Key Laboratory of Adaptation and Evolution of Plateau Biota, Northwest Institute of Plateau Biology, Chinese Academy of Sciences, Qinghai Province, under the accession numbers KLAEPB No.019001, China.

\section{Ethics approval and consent to participate}

This study was conducted under the protocol of the Ethical Commission of the Northwest Institute of Plateau Biology, Chinese Academy of Sciences and Hebei Normal University. All applicable institutional, national and international guidelines for the protection and use of animals were followed.

\section{Consent for publication}

Not applicable.

\section{Competing interests}

The authors declare that they have no conflict of interest.

\section{Author details}

${ }^{1}$ Key Laboratory of Adaptation and Evolution of Plateau Biota (AEPB), Northwest Institute of Plateau Biology, Chinese Academy of Sciences, Xining 810008, Qinghai, People's Republic of China. ${ }^{2}$ Qinghai Key Laboratory of Animal Ecological Genomics, Northwest Institute of Plateau Biology, Chinese Academy of Sciences, Xining 810008, People's Republic of China. ${ }^{3}$ Key Laboratory of Animal Physiology, Biochemistry and Molecular Biology of Hebei Province, College of Life Sciences, Hebei Normal University, Shijiazhuang 050024, Hebei Province, People's Republic of China. ${ }^{4}$ University of Chinese Academy of Sciences, Beijing 100093, People's Republic of China.

Received: 29 August 2020 Accepted: 26 October 2020

Published online: 11 November 2020

References

1. Schaller GB. Wildlife of the Tibetan steppe. Chicago: University of Chicago Press; 1998. p. 373.

2. Leslie DMJ, Schaller GB. Pantholops hodgsonii (Artiodactyla: Bovidae). Mamm Spe. 2008;817:1-13.

3. Yang GY. Advance on parasites and parasitosis of giant panda. Chin J Vet Sci. 1998;18:158-208.

4. Zhang JS, Daszak P, Huang HL, Yang GY, Kilpatrick AM, Zhang S. Parasite threat to panda conservation. EcoHealth. 2008;5:6-9.

5. Smith KF, Sax DF, Lafferty KD. Evidence for the role of infectious disease in species extinction and endangerment. Conserv Biol. 2006;20:1349-57.

6. Wisely SM, Howard J, Williams SA, Bain O, Santymire RM, Bardsley KD, et al. An unidentified filarial species and its impact on fitness in wild populations of the black-footed ferret (Mustela nigripes). J Wildl Dis. 2008;44:53-64.

7. Zhang L, Yang XY, Wu H, Gu XD, Hu YB, Wei FW. The parasites of giant pandas: Individual-based measurement in wild animals. J Wildl Dis. 2011:47:164-71.

8. Cai JZ, Ma YQ, Yu MS, Wang M, Li CH, Liu SC, et al. Investigation on warble larva infestion in Tibeten antilopes. Chin J Vet Med. 2006:42:25-6.

9. Peng C, Cai JZ, Cao XC, Li CH, Cao J, Xu MQ, et al. A fourth species of Hypoderma (Diptera: Oestridae) found from Tibetan antelope in China. Acta Entomol Sinica. 2008;51:1099-102.

10. $\mathrm{Wu} X \mathrm{XM}, \mathrm{Hu} \mathrm{H}$, Zhang HF, Che LF, Qiao JY. Parasite infection status in Tibetan antelope. J Econ Anim. 2013;17:63-6. 
11. Cao YF, Su JP, Zhang TZ, Lian XM. Parasitic helminth eggs in the feces of Tibetan Antelope. Chin J Zool. 2006:41:91-3.

12. Cao YF, Yang YB, Duszynski DW, Zhu YH, Zhang TZ, Shang GZ, et al. Five new species of Eimeria Schneider, 1875 from the endangered Tibetan antelope Pantholops hodgsonii (Abel) (Artiodactyla: Bovidae: Caprinae) in the Hoh Xil Nature Reserve Area of Qinghai Province. China Syst Parasitol. 2019;96:337-46.

13. Floyd RM, Rogers AD, Lambshead JD, Smith CR. Nematode-specific PCR primers for the 18S small subunit rRNA gene. Mol Ecol. 2005;5:611-6.

14. Nadler SA, Hudspeth DSS. Ribosomal DNA and phylogeny of the Ascaridoidea (Nemata: Secernentea): implications for morphological evolution and classification. Mol Phylogenet Evol. 1998;10:221-36.

15. Zhu X, D'Amelio S, Paggi L, Gasser RB. Assessing sequence variation in the internal transcribed spacers of ribosomal DNA within and among members of the Contracaecum osculatum complex (Nematoda: Ascaridoidea: Anisakidae). Parasitol Res. 2000;86:677-83.

16. Li L, Lü L, Nadler SA, Gibson DI, Zhang LP, Chen HX, et al. Molecular phylogeny and dating reveal a terrestrial origin in the early carboniferous for ascaridoid nematodes. Syst Biol. 2018;67:888-900.

17. Iczn International Commission on Zoological Nomenclature: Amendment of articles 8, 9, 10, 21 and 78 of the International Code of Zoological Nomenclature to expand and refine methods of publication. Bull Zool Nomencl. 2012;69:161-9.

18. Mönnig HO. Wild antelopes as carriers of nematode parasites of domestic ruminants. Part II. 18th Annual Report of the Director of Veterinary Services, Department of Agriculture, Union of South Africa. 1932; 152-72.

19. Dikmans G. A new nematode Skrjabinema parva (Nematoda: Oxyuroidea) from deer. Proc Helminthol Soc W. 1942;9:66-8.

20. Olsen OW, Tolman CD. Description of the male of the pinworm, Skrjabinema parva Dilmans, 1942 (Nematoda: Oxyuridea) from deer, with an emendation of the genus. J Parasitol. 1950;36:411-5.

21. Schad GA. A revision of the North American species of the genus Skrjabinema (Nematoda: Oxyuroidea). Proc Helminthol Soc W. 1959;26:138-47.

22. Skrjabin Kl, Shikhobalova NP, Lagodovskaya EA. Oxyurata of animals and man, Part one: Oxyuroidea. Moscow: Izdatel'stvo Akademii Nauk SSSR; 1960. p. 502.

23. Gagarin VG, Sapozhnikov Gl. Revision of some species of Skrjabinema Werestschagin, 1926. In: Podyapolskaya VP, Shikhobalova NP, Ryzhikov KM, editors. Helminths of humans, animals Paramonov, Izdatel'stvo Akademii Nauk SSSR. Moscow: Russia; 1968. p. 131-40.

24. Hasegawa H, Sato H, Suzuki K, Kaneshiro Y. A new Oxyurid species (Nematoda) collected from a Japanese serow, Capricornis crispus (Mammalia: Bovidae), in Japan. J Parasitol. 2012;98:1161-5.

25. Hu GW, Ma RL, Cai JS, Zhao QB, Li LF, Ma ZQ, et al. The first discovery nematodae of Skrjabinema ovis in the Qaidam area. China Chin J Vet Med. 2012;48:49-50
26. Li Y, Chen HX, Yang XL, Li L. Morphological and genetic characterization of Syphabulea tjanschani (Ablasov, 1962) (Nematoda: Oxyuridae), with phylogenetic position of Syphabulea in Oxyuridae. Infect Genet Evol. 2019;67:159-66.

27. Nakano T, Okamoto M, Ikeda Y, Hasegawa H. Mitochondrial cytochrome c oxidase subunit 1 gene and nuclear rDNA regions of Enterobius vermicularis parasitic in captive chimpanzees with special reference to its relationship with pinworms in humans. Parasitol Res. 2006;100:51-7.

28. Parel JD, Galula JU, Ooi HK. Characterization of rDNA sequences from Syphacia obvelata, Syphacia muris and Aspiculuris tetraptera and development of a PCR-based method for identification. Vet Parasitol. 2008;153:379-83.

29. Koehler AV, Borel S, Hoby S, Hentrich B, Gottstein B, Gasser RB. Genetic identification of an oxyurid from a captive, black-handed spider monkey -implications for treatment and control. Parasitol Res. 2014;113:3445-8

30. Solórzano-García B, Nadler SA, de León GPP. Trypanoxyuris atelis and T. atelophora (Nematoda: Oxyuridae) in wild spider monkeys (Ateles geoffroyi) in tropical rain forest in Mexico: Morphological and molecular evidence. Parasitol Int. 2015:64:229-35.

31. Solórzano-García B, Nadler SA, de León GPP. Pinworm diversity in freeranging howler monkeys (Alouatta spp.) in Mexico: Morphological and molecular evidence for two new Trypanoxyuris species (Nematoda: Oxyuridae). Parasitol Int. 2016;65:401-11.

32. Pereira FB, Luque JL, Tavares LER. Integrative approach on Pharyngodonidae (Nematoda: Oxyuroidea) parasitic in reptiles: Relationship among its genera, importance of their diagnostic features, and new data on Parapharyngodon bainae. PLoS ONE. 2018;13:e0200494.

33. Erkulov E, Moldopiyazova P. Syphaciidae in rodents in Southern Kirgizia, USSR. In: Tokobaev MM, editor. Helminthological studies in Kirgizia. Izdatel'stvo: USSR; 1975. p. 36-49.

34. Hugot JP. Les Syphaciinae (Oxyuridae) parasites de Sciurides. Evolution des genres Syphatineria et Syphabulea. Mem Mus Natn Hist Nat. 1981;121:1-64.

\section{Publisher's Note}

Springer Nature remains neutral with regard to jurisdictional claims in published maps and institutional affiliations.
Ready to submit your research? Choose BMC and benefit from:

- fast, convenient online submission

- thorough peer review by experienced researchers in your field

- rapid publication on acceptance

- support for research data, including large and complex data types

- gold Open Access which fosters wider collaboration and increased citations

- maximum visibility for your research: over $100 \mathrm{M}$ website views per year

At BMC, research is always in progress.

Learn more biomedcentral.com/submissions 